\title{
Insufficient radiofrequency ablation promotes epithelial-mesenchymal transition of hepatocellular carcinoma cells through Akt and ERK signaling pathways
}

Shuying Dong ${ }^{1+}$, Jian Kong ${ }^{1+}$, Fandong Kong ${ }^{1+}$, Jinge Kong ${ }^{3}$, Jun Gao ${ }^{1}$, Shan Ke ${ }^{1}$, Shaohong Wang ${ }^{1}$, Xuemei Ding ${ }^{1}$, Wenbing Sun ${ }^{1^{*}}$ and Lemin Zheng $^{2^{*}}$

\begin{abstract}
Background: Residual tumor progression after insufficient radiofrequency ablation (RFA) has been recently reported. However, whether epithelial-mesenchymal transition (EMT), which is a key process that drives cancer metastasis, is involved in the tumor progression after insufficient RFA is not well understood.
\end{abstract}

Methods: Human hepatocellular carcinoma (HCC) cell lines SMMC7721 and Huh7 were used. Insufficient RFA was simulated using a water bath $\left(47^{\circ} \mathrm{C} 5 \mathrm{~min}, 10 \mathrm{~min}, 15 \mathrm{~min}, 20 \mathrm{~min}\right.$ and $25 \mathrm{~min}$ gradually). MTT assay was used to evaluate the proliferation of HCC cells in vitro. Migration and invasion of HCC cells were determined by transwell assay. The molecular changes in HCC cells after insufficient RFA were evaluated by western blot. LY294002 and PD98059 were used to treat HCC cells. An ectopic nude mice model and a tail vein metastatic assay were used to evaluate the growth and metastatic potential of SMMC7721 cells in vivo after insufficient RFA.

Results: SMMC7721 and Huh7 cells after insufficient RFA (named as SMMC7721-H and Huh7-H respectively) exhibited enhanced proliferation, migration and invasion (6.4\% and $23.6 \%, 33.2 \%$ and $66.1 \%$, and $44.1 \%$ and $57.4 \%$ increase respectively) in vitro. Molecular changes of EMT were observed in SMMC7721-H and Huh7-H cells. LY294002 and PD98059 inhibited the EMT of SMMC7721-H and Huh7-H cells. SMMC7721-H cells also exhibited larger tumor size $\left(1440.8 \pm 250.3 \mathrm{~mm}^{3}\right.$ versus $\left.1048.56 \pm 227.6 \mathrm{~mm}^{3}\right)$ and more lung metastasis (97.4\% increase) than SMMC7721 cells in vivo. Higher expression of PCNA, N-cadherin and MMP-2 and MMP-9, was also observed in SMMC7721-H tumors.

Conclusions: Insufficient RFA could directly promote the invasiveness and metastasis of HCC cells. Insufficient RFA may promote the EMT of HCC cells through Akt and ERK signaling pathways.

Keywords: Insufficient radiofrequency ablation, Epithelial-mesenchymal transition, Hepatocellular carcinoma, Metastasis

\footnotetext{
* Correspondence: wb.sun@yahoo.com.cn; Zhengl@bjmu.edu.cn

${ }^{\dagger}$ Equal contributors

${ }^{1}$ Department of Hepatobiliary Surgery, Beijing Chaoyang Hospital, Capital

Medical University, Beijing 100043, China

${ }^{2}$ The Institute of Cardiovascular Sciences and Institute of Systems

Biomedicine, School of Basic Medical Sciences, Peking University Health

Science Center, Key Laboratory of Molecular Cardiovascular Sciences of

Education Ministry, and Key Laboratory of Cardiovascular Molecular Biology

and Regulatory Peptides of Health Ministry, Beijing 100191, China

Full list of author information is available at the end of the article
} 


\section{Background}

Hepatocellular carcinoma (HCC) is the fifth most common cancer in men and the seventh in women worldwide [1]. Radiofrequency ablation (RFA) is one of the treatments for HCC and is now widely used for curative strategies [2]. However, for the RFA procedure to be considered technically successful, the tumor and a safety margin of at least $5 \mathrm{~mm}$ of normal hepatic tissue must be completely included in the ablation zone [3], therefore the major problem with RFA is its difficulty in achieving complete tumor destruction [4].

Residual tumor progression after insufficient RFA has been recently reported and two possible mechanisms also have been proposed. RFA may alter tumor microenvironment to enhance the outgrowth of residual tumor cells. RFA could accelerate perinecrotic outgrowth of colorectal liver metastases in a hypoxia-dependent manner $[4,5]$. Another study showed that thermal ablation promoted the progression of micrometastases to form macroscopically detectable neoplasms in treated regenerating liver through an increased expression of vascular endothelial growth factor (VEGF) and fibroblast growth factor-2 (FGF-2) adjacent to the treatment site [6]. Our previous study also showed that tumor-associated endothelial cells after insufficient RFA exhibited enhanced angiogenesis and promoted invasiveness of residual HCC [7]. Alternatively, RFA could directly influence tumor cells to promote progression of residual tumor. Our previous studies demonstrated that HCC cells after insufficient RFA induced angiogenesis via hypoxia inducer factor (HIF-1) $\alpha$ / VEGFA in vitro [8], and insufficient RFA could facilitate the growth and metastasis of residual hepatic VX2 carcinoma owing to the induction of over-expression of PCNA, VEGF and MMP-9 [9]. Another study also indicated that insufficient RFA may induce further malignant transformation of HCC [10]. However, rapid progression of residual tumor after insufficient RFA is a complex process and further mechanisms need to be elucidated. Metastases, termed the invasion-metastasis cascade, involve dissemination of cancer cells to anatomically distant organ sites and their subsequent adaptation to foreign tissue microenvironments [11], which $90 \%$ of mortality from cancer is attributable to [12]. Whether insufficient RFA could directly promote invasion-metastasis of residual HCC cells and the mechanisms involved in the process have not been clearly determined.

Epithelial-mesenchymal transition (EMT) is a key process that drives cancer metastasis, and it is characterized by loss of the epithelial marker, increased expression of the mesenchymal marker, and enhanced migratory and invasive behaviors $[13,14]$. Characteristic down-regulation of E-cadherin is regarded as the key step to EMT. HCCs with EMT features consistently exhibit more venous invasion, metastases, and a poorer prognosis than those without EMT characteristics [15]. Whether insufficient RFA directly induces the EMT of residual HCC cells and further promotes the metastasis remains unclear.

In the present study, we investigated the morphological changes, cell growth, migration and invasion of HCC cell lines (SMMC7721 and Huh7) after insufficient RFA in vitro. Furthermore, we analyzed the changes of epithelial and mesenchymal markers, and Akt and ERK1/2 signaling pathways involved in the process in HCC cells after insufficient RFA. We also performed in vivo experiments to study the growth and metastasis of HCC cells after insufficient RFA in a BALB/c nu/nu mice model.

\section{Methods}

\section{Cell culture}

Established human HCC cell lines, SMMC7721 and Huh7 were from the American Type Culture Collection (ATCC; Manassas, VA, USA). All cells were maintained in high-glucose Dulbecco's modified Eagle medium (DMEM) supplement with $10 \%$ fetal bovine serum (FBS), $100 \mathrm{U} / \mathrm{ml}$ penicillin and $100 \mu \mathrm{g} / \mathrm{ml}$ streptomycin (Life Technologies, Cergy Pontoise, France) in a humidified atmosphere of $5 \% \mathrm{CO}_{2}$ at $37^{\circ} \mathrm{C}$.

\section{Chemicals and antibodies}

LY294002 and PD98059 were purchased from Beyotime (Jiangsu, China). Antibodies with specificity for the phosphorylated forms of Akt and ERK1/2 were purchased from Cell signaling (Beverly, CA, USA). Antibodies recognizing E-cadherin, $\mathrm{N}$-cadherin, vimentin, snail and $\alpha$-SMA were bought from Abcam (Cambridge, TX, USA). Antibodies recognizing $\beta$-actin, MMP-2 and MMP-9 antibodies were obtained from Santa Cruz (Dallas, TX, USA).

\section{Heat treatment}

Insufficient RFA was simulated in vitro as described before [8]. Briefly, SMMC7721 or Huh7 cells were seeded into the 6 -well plates $\left(5 \times 10^{4}\right.$ cells/well $)$. After $24 \mathrm{~h}$, the plates were sealed and submerged in a water bath set to $47^{\circ} \mathrm{C}$ for $5 \mathrm{~min}$. Thereafter, cells were allowed to recover, and when the surviving populations reached $80 \%$ confluence, cells were propagated into the 6-well plates and exposed to above heat treatment for $10 \mathrm{~min}$. Then the process was repeated and cells were sequentially exposed to above heat treatment for $15 \mathrm{~min}, 20 \mathrm{~min}$ and $25 \mathrm{~min}$. Cells survived from the treatment were designated as SMMC7721-H and Huh7-H respectively. The morphological characteristics of HCC cells were observed by microscopy (Olympus, Tokyo, Japan).

\section{Proliferation assay}

Cell proliferation was analyzed using the 3-(4, 5dimethylthiazol-2-yl)-2, 5-diphenyltetrazolium bromide 
(MTT) assay. Briefly, HCC cells were cultured in 96-well plates at a concentration of $3 \times 10^{3}$ cells/well, and incubated for $24 \mathrm{~h}, 48 \mathrm{~h}$, or $72 \mathrm{~h}$. MTT solution was added to each well at a final concentration of $0.5 \mathrm{mg} / \mathrm{ml}$ and incubated for $4 \mathrm{~h}$. At the end of incubation, formazan crystals resulting from MTT reduction were dissolved by addition of $150 \mu \mathrm{l}$ dimethyl sulfoxide per well. The absorbance was measured at $570 \mathrm{~nm}$ using an automated ELISA plate reader.

\section{Colony formation assay}

HCC cells were seeded into 6-well dishes at a concentration of $1 \times 10^{3}$ cells/well and allowed to grow in complete medium for 2 weeks. The colonies obtained were washed with PBS and fixed in $4 \%$ paraformaldehyde for $20 \mathrm{~min}$ at room temperature and then washed with PBS followed by staining with crystal violet. The colonies were counted and compared with untreated cells.

\section{Migration and invasion assay}

Quantitative cell migration assays were performed using a modified Boyden chamber (Costar-Corning, New York, USA) with $8.0-\mu \mathrm{m}$ pore polycarbonate filter inserts in 24-well plates as described previously. Briefly, the lower chamber was filled with DMEM with $10 \%$ FBS, and HCC cells $\left(5 \times 10^{4}\right.$ cells/well $)$ in serum-free medium were added into the upper chamber. The cells were allowed to migrate for $24 \mathrm{~h}$ at $37^{\circ} \mathrm{C}$. The non-migrated cells were removed from the upper surface of the membrane by scraping with a cotton swab, and the migrating cells were fixed with methanol, stained with crystal violet (Beyotime, Nantong, China) and photographed under an inverted fluorescence microscope (Olympus IX51) equipped with an Olympus Qcolor 3 digital camera (Olympus). Migration was assessed by counting the number of stained cells from 10 random fields at $\times 200$ magnification. Cell invasion assay was performed similarly, except that transwell inserts were matrigel-coated.

\section{Western blot}

HCC cells were lysed with lysis buffer $[150 \mathrm{mM} \mathrm{NaCl}$, $50 \mathrm{mM}$ Tris- $\mathrm{HCl}$ (pH 8.0), 0.1\% SDS, 1\% Triton X-100] containing protease and phosphatase inhibitor $(1 \mathrm{mM}$ Phenylmethanesulfonyl fluoride and $1 \mathrm{mM}$ Sodium orthovanadate). Cell lysate protein content was determined using a Bicinchoninic acid (BCA) protein assay kit. Equivalent amounts of whole cell extracts were subjected to SDS-PAGE and transferred to nitrocellulose membranes. The membranes were blocked with $5 \%$ non-fat milk for $2 \mathrm{~h}$ and then incubated with respective primary antibody overnight at $4^{\circ} \mathrm{C}$ followed by the incubation with the appropriate HRP-conjugated secondary antibody for $1.5 \mathrm{~h}$ at room temperature. Blots were visualized with an ECL detection kit (Pierce, USA) and analyzed using Quantity One 1-D Analysis Software (Bio-Rad, Hercules, USA).

\section{Inhibitors}

LY294002 or PD98059 was used to inhibit the expression of p-Akt or p-ERK1/2 in HCC cells. Briefly, LY294002 or PD98059 was added to the culture media of HCC cells at a final concentration of $25 \mu \mathrm{M}$ or $50 \mu \mathrm{M}$, after $24 \mathrm{~h}$, cell lysate protein was collected, and western blot was conducted. In the migration and invasion assays, LY294002 $(25 \mu \mathrm{M})$ or PD98059 $(25 \mu \mathrm{M})$ was added to the upper chamber, and after $24 \mathrm{~h}$ the chambers were collected.

\section{Animals}

Male BALB/c nu/nu mice (4-6 weeks old) were obtained from Vital River Laboratories (Beijing, China) and maintained under standard pathogen-free conditions. The animal welfare guidelines for the care and use of laboratory animals were approved by the Animal Care Committee of Capital Medical University (Beijing, China).

\section{Xenograft assays}

SMMC7721 cells $\left(5 \times 10^{6}\right.$ cells $)$ were suspended in $200 \mu \mathrm{l}$ serum-free DMEM and matrigel (1:1) and then injected subcutaneously into the upper right flank region of 12 nude mice. Tumor size was measured with a caliper rule every 3 days. The tumor volume was estimated with the formula " $\mathrm{a} \times \mathrm{b}^{2} \times 0.5$ ", in which a represented the longest and $\mathrm{b}$ the shortest radius of the tumor in millimeters. At the end of the experiments, mice were euthanized, blood samples were collected via cardiac puncture, and tumor tissues were removed for fixation in the $4 \%$ paraformaldehyde for histologic examination and immunohistochemical staining.

\section{Tail vein metastatic assays}

HCC cells $\left(1 \times 10^{6}\right.$ cells $)$ were suspended in $100 \mu$ PBS and injected through tail vein. Four weeks after the injection, the mice were sacrificed and the lung tissues were isolated. After counting the number of visible tumors on lung surface, the lung tissues were made into serial sections before HE staining and observed under a light microscope.

\section{Immunocytochemistry}

Tissues were fixed in $4 \%$ paraformaldehyde and subsequently embedded in paraffin. Paraffin-embedded tissue sections were cut into standard $6 \mu \mathrm{m}$ sections, deparaffinaged in xylene and rehydrated through graded alcohol solutions. Antigen retrieval was performed $10 \mathrm{~min}$ at $92^{\circ} \mathrm{C}$ in EDTA (10 mM, pH 8.0) in a water bath. Endogenous peroxidases were inactivated by immersing the sections in $0.3 \%$ hydrogen peroxide for $12 \mathrm{~min}$. The sections were blocked with $5 \%$ goat serum for $60 \mathrm{~min}$ at $37^{\circ} \mathrm{C}$. The slides 
were incubated with primary antibodies for overnight at $4^{\circ} \mathrm{C}$. Next, the slides were treated with appropriate HRP-conjugated secondary antibodies for $40 \mathrm{~min}$ at $37^{\circ} \mathrm{C}$ and then developed with 3,3'-diaminobenzidine. Finally, the slides were counterstained with hematoxylin and mounted. The slides were examined with Nikon Eclipse Ti microscope under $\mathrm{a} \times 200$ objective.

\section{Statistical analysis}

All values are expressed as the mean \pm SEM. The data were analyzed using Student's t test or the ANOVA test. A $P$ value of $<0.05$ was considered statistically significant. GraphPad Prism (GraphPad Software Inc., San Diego, California, USA) was used for these analyses.

\section{Results}

Insufficient RFA promoted HCC cells proliferation, migration and invasion

To evaluate the effect of insufficient RFA on HCC cells, SMMC7721 and Huh7 cells were treated with heat treatment $\left(47^{\circ} \mathrm{C}\right.$ in a water bath) for $5 \mathrm{~min}, 10 \mathrm{~min}, 15 \mathrm{~min}$, $20 \mathrm{~min}$ and $25 \mathrm{~min}$ gradually as described previously [8]. Three independent SMMC7721-H or Huh7-H cell lines have ever been developed, and biological behavior of each SMMC7721-H or Huh7-H cell line was similar. The results of one of each were shown. SMMC7721-H exhibited higher proliferation rate compared with SMMC-7721 at $24 \mathrm{~h}, 48 \mathrm{~h}$, and $72 \mathrm{~h}(7.6 \%, 9.9 \%$ and $6.4 \%$ increase respectively) (Figure $1 \mathrm{~A}$ ). To determine the long term growth ability, HCC cells were allowed to grow for 2 weeks. SMMC7721-H cells had a higher number of colonies in comparing with SMMC7721 cells (Figure 1B). SMMC7721-H cells also displayed enhanced migration and invasion abilities (33.2\% and 44.1\% increase respectively) compared with SMMC7721 cells (Figure 1C). Similar patterns of cell proliferation, migration and invasion were also found in Huh7-H and Huh7 cells (Figure 1).

\section{Insufficient RFA promoted EMT of HCC cells}

Interestingly, we found that SMMC7721- $\mathrm{H}$ and $\mathrm{Huh} 7-\mathrm{H}$ displayed a spindle shape with less cell-cell adhesion and increased formation of pseudopodia (Figure 2A). To evaluate whether EMT had occurred in SMMC7721- $\mathrm{H}$ and Huh7-H cells, EMT markers were examined. Western blot showed significant reduction in E-cadherin expression and up-regulation of N-cadherin, vimentin, $\alpha$-SMA, fibronectin, MMP-2 and MMP-9 (Figure 2B).

\section{Insufficient RFA promoted EMT of HCC cells through Akt and ERK $1 / 2$ signaling pathways}

To explore the signaling mechanisms involved in the EMT of HCC cells after insufficient RFA, we tested Akt and ERK1/2 signaling pathways. SMMC7721-H showed significantly increased expression of p-Akt and p-ERK1/ 2 compared with SMMC7721 (Figure 3A). Furthermore, an up-regulation of the transcription factor snail was also detected in SMMC7721-H (Figure 3A). PI3K/Akt inhibitor LY294002, or ERK1/2 inhibitor PD98059 significantly suppressed the expression of p-Akt or pERK1/2 in SMMC7721 and SMMC7721-H cells respectively, also inhibited the expression of $\mathrm{N}$-cadherin and snail, and increased the expression of E-cadherin (Figure 3B). LY294002 or PD98059 also suppressed the migratory and invasive ability of SMMC7721 and SMMC7721-H (Figure 3C and D). The significant difference of migratory and invasive ability of SMMC7721 and SMMC7721-H cells was also eliminated after LY294002 or PD98059 was used (Figure 3C and D). Similar results were also found in Huh7 and Huh7-H cells (Additional file 1).

Insufficient RFA enhanced the growth of HCC cells in vivo To examine the effects of insufficient RFA on tumor growth in vivo, we evaluated the effect in a SMMC7721 ectopic HCC model. SMMC7721-H cells showed increased tumor volume compared with SMMC7721 cells $\left(1440.8 \pm 250.3 \mathrm{~mm}^{3}\right.$ versus $\left.1048.56 \pm 227.6 \mathrm{~mm}^{3}\right)$ (Figure 4A). Significant increases of cell proliferation were observed by PCNA in SMMC7721-H tumors. In addition, SMMC7721-H tumors showed decreased expression of E-cadherin and increased expression of $\mathrm{N}$-cadherin, MMP-2 and MMP-9 compared with SMMC7721 tumors (Figure 4B). However, there were no apparent changes in body weight in the mice (Additional file $2 \mathrm{~A}$ ).

\section{HCC cells exhibited enhanced metastatic ability in vivo after insufficient RFA}

To determine the effects of insufficient RFA on the in vivo metastasis of SMMC7721 cells, a tail vein metastasis assay was used. The extent of the metastatic tumors on the surface of the lung was significantly increased (97.4\% increase) in mice receiving SMMC7721-H cells compared with SMMC7721 cells (Figure 5A). The lung tissues were sectioned serially and $\mathrm{HE}$ staining also confirmed the results above (Figure $5 \mathrm{~B}$ and $\mathrm{C}$ ). However, there were no apparent changes in body weight in the mice (Additional file 2B).

\section{Discussion}

RFA is safe and more effective than resection for very early $\mathrm{HCC}$ and in the presence of two or three nodules $<3 \mathrm{~cm}$, however, its ability to obtain complete and sustained tumor necrosis is less predictable [16]. So to further elucidate the biological behavior of residual HCC, involved mechanisms after insufficient RFA is important to improve prognosis of HCC patients. In the present study, we demonstrated that insufficient RFA promoted the growth, 

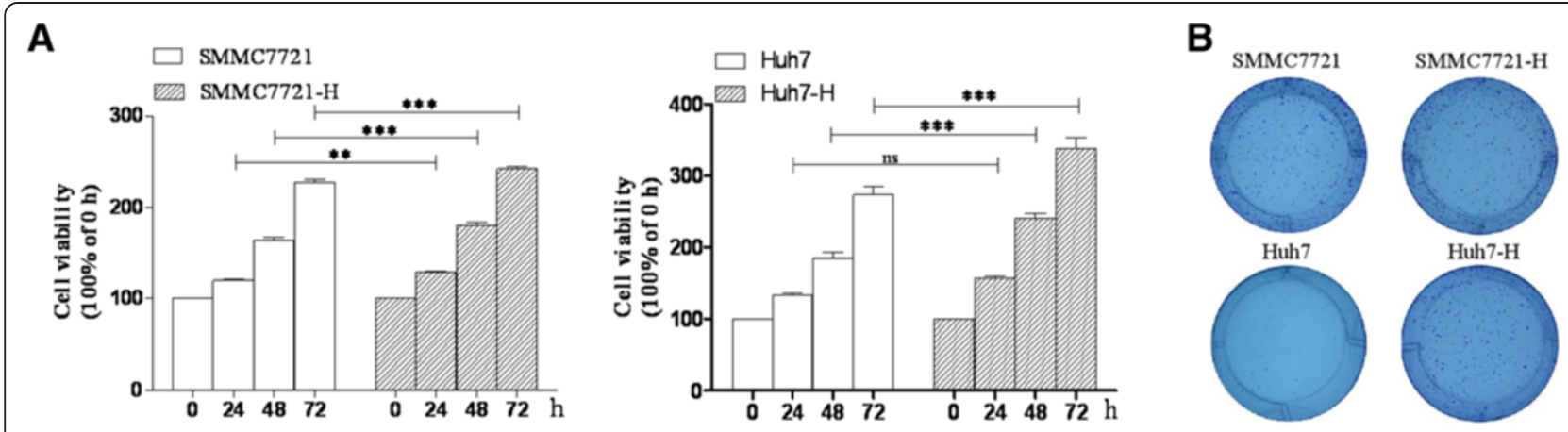

C
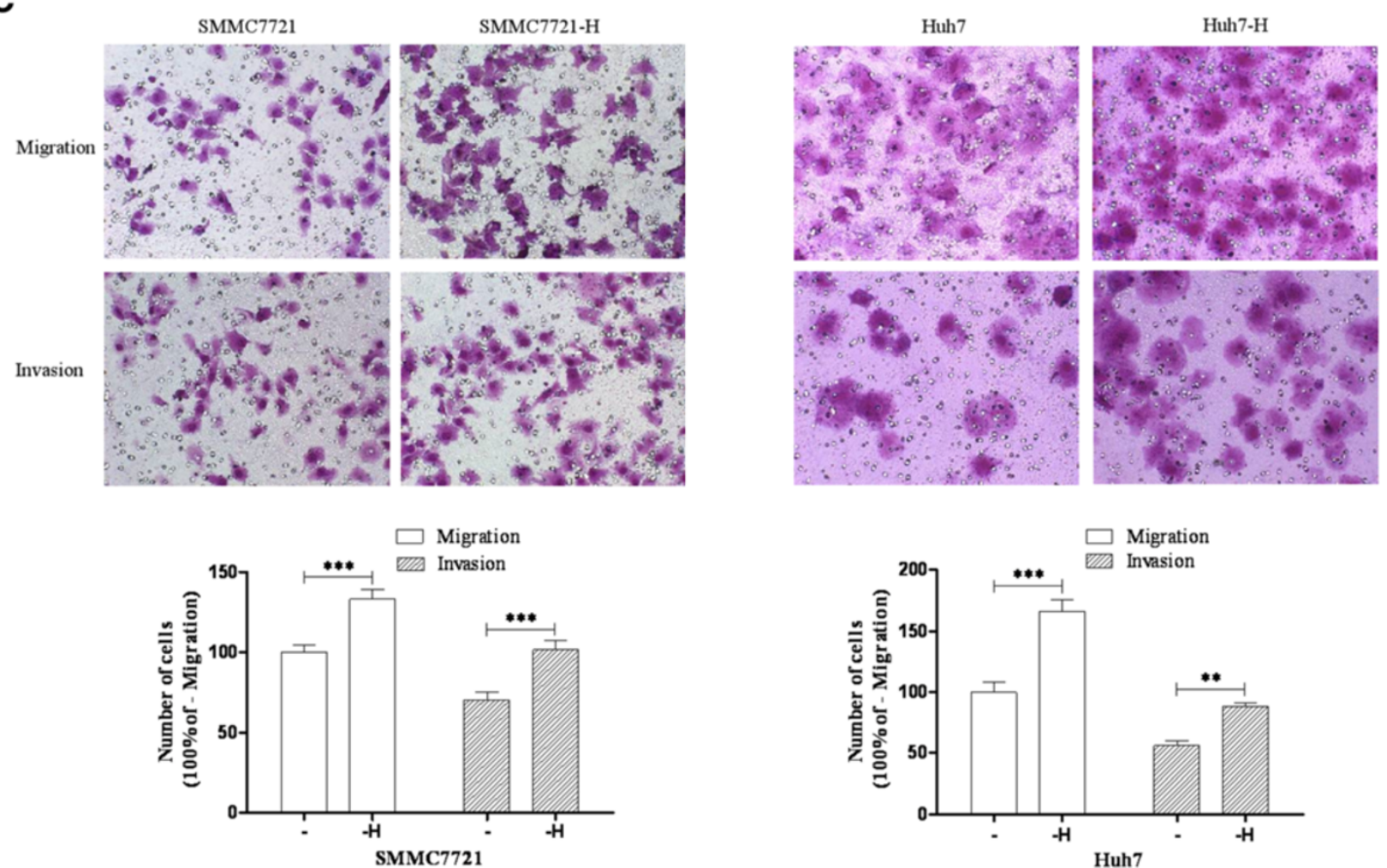

Figure 1 Insufficient RFA promoted the proliferation, colony formation, migration and invasion of HCC cells. SMMC7721 and Huh7 cells were treated with insufficient RFA $\left(47^{\circ} \mathrm{C} 5 \mathrm{~min}, 10 \mathrm{~min}, 15 \mathrm{~min}, 20 \mathrm{~min}\right.$ and $25 \mathrm{~min}$ ) gradually. Residual SMMC7721 and Huh7 (named as SMMC7721-H and Huh7-H respectively) cells were collected and used for the next experiments. (A) Proliferation rate of SMMC7721, SMMC7721-H, Huh7 and Huh7-H was evaluated by MTT assay. Error bars represent the SEM of data obtained in five independent experiments. (B) Colony formation abilities of SMMC7721, SMMC7721-H, Huh7 and Huh7-H cells were assessed. Error bars represent the SEM of data obtained in three independent experiments. (C) Migration and invasion of SMMC7721, SMMC7721-H, Huh7 and Huh7-H cells were shown. Error bars represent the SEM of data obtained in three independent experiments. P value $<0.05$ was considered statistically significant; ${ }^{* * *} p<0.001,{ }^{* *} p<0.01$.

migration and invasive potential of HCC cells. Furthermore, enhanced migration and invasion of HCC cells after insufficient RFA were associated with EMT. In addition, rapid growth and enhanced metastasis of HCC cells after insufficient RFA in vivo further confirmed the results in vitro. Our results have demonstrated that EMT plays an important role in enhancing invasiveness and metastasis of HCC cells after insufficient RFA.

Our previous study elucidated that one sub-line selected from HepG2 cells after insufficient RFA $\left(47^{\circ} \mathrm{C}\right.$
10 min) exhibited more rapid proliferation rate [8]. Although in the present study SMMC7721 and Huh7 cells were treated with insufficient RFA gradually $\left(47^{\circ} \mathrm{C}\right.$ $5 \mathrm{~min}, 10 \mathrm{~min}, 15 \mathrm{~min}, 20 \mathrm{~min}$, and $25 \mathrm{~min}$ ), the surviving SMMC7721-H and Huh7-H cells also showed higher proliferation rate compared with SMMC7721 and Huh7 cells respectively. Interestingly, in the present study, SMMC7721 and Huh7 cells after insufficient RFA displayed a spindle shape with less cell-cell adhesion and increased formation of pseudopodia. So we inferred that 

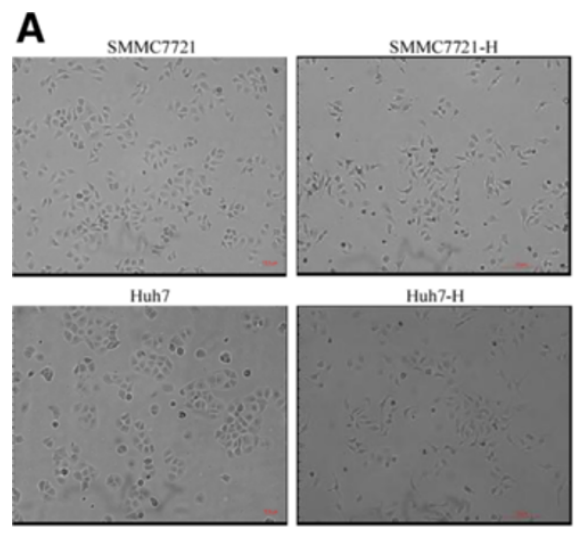

B

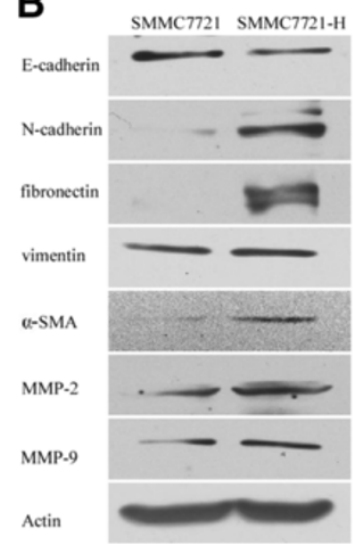

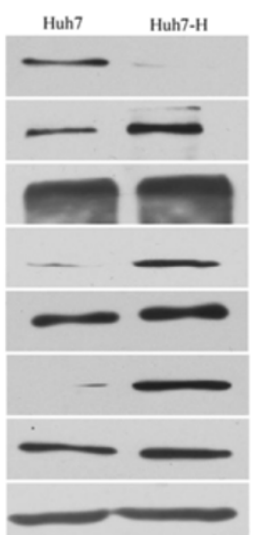

Figure 2 Insufficient RFA induced EMT in HCC cells. (A) The morphological changes of SMMC7721 and Huh7 cells after insufficient RFA were displayed. (B) Cell extracts were subjected to western blot analysis and expression of E-cadherin, N-cadherin, fibronectin, vimentin, a-SMA, MMP-2 and MMP-9 were detected. Actin served as loading control.

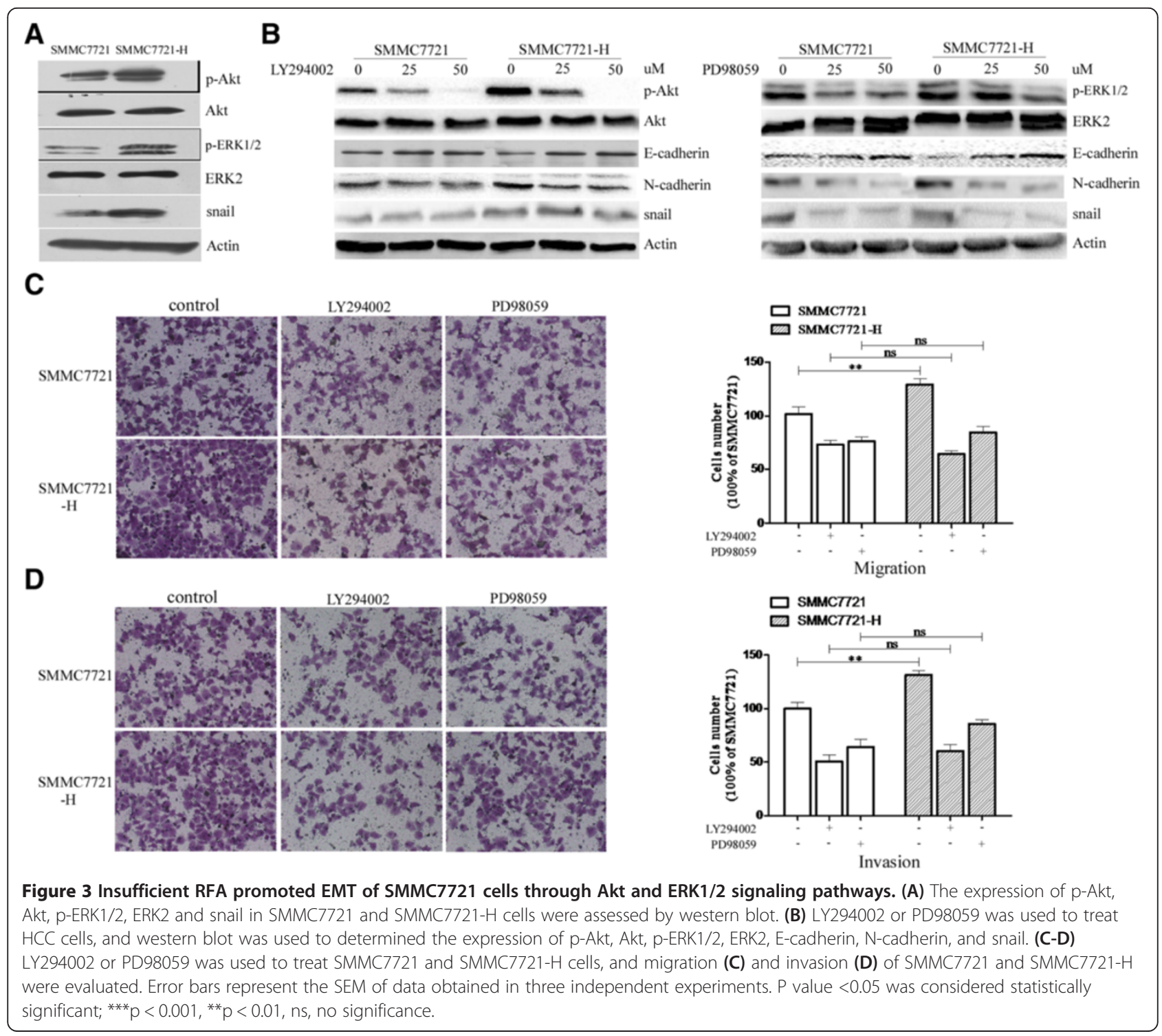



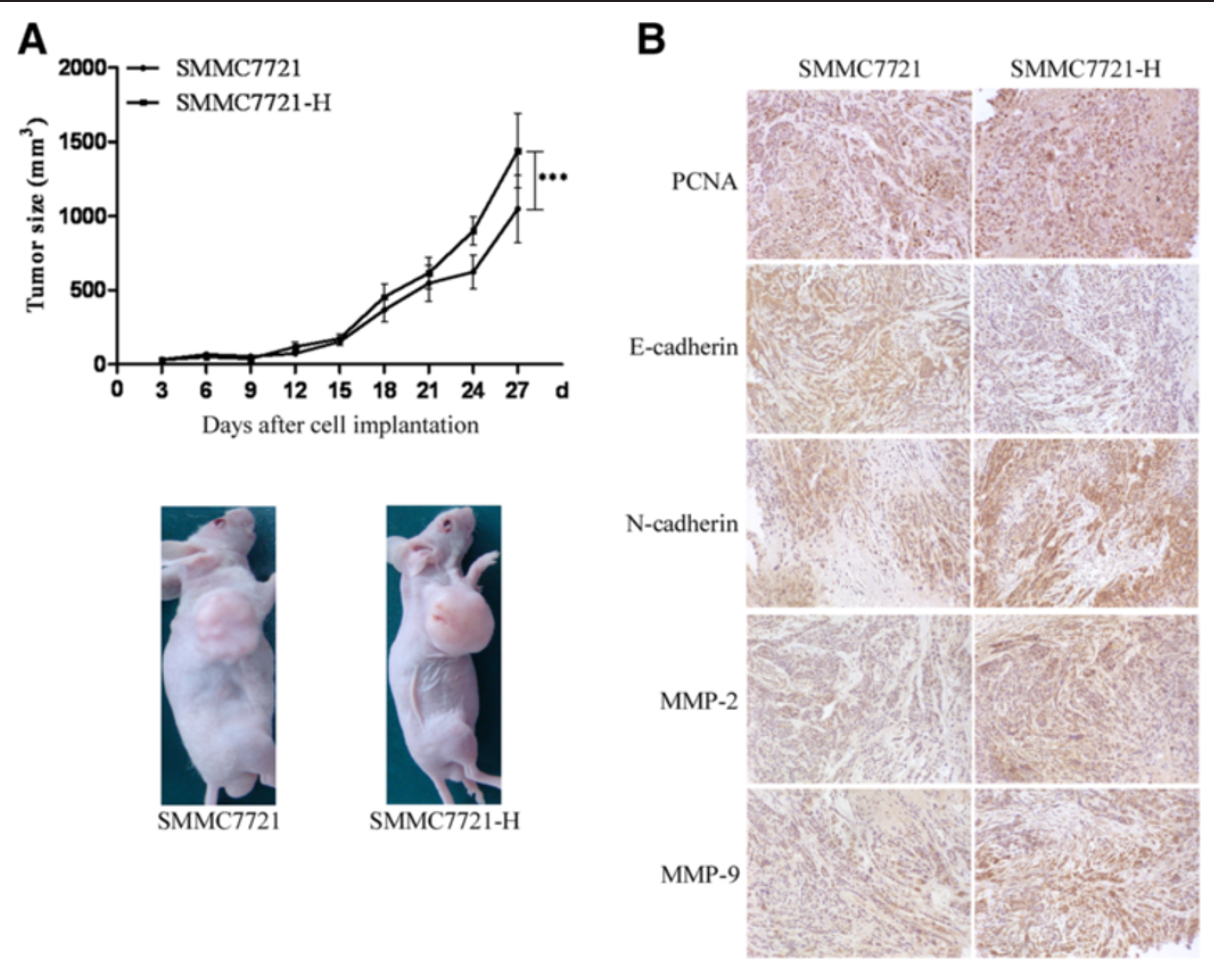

Figure 4 Insufficient RFA promoted the growth of HCC cells in vivo. SMMC7721 and SMMC7721-H cells were injected subcutaneously into the upper right flank region of nude mice and tumor volume was measured. (A) Tumor volume was measured with a caliper rule every 3 days. Data were presented as the mean tumor volumes of mice. Representative images of tumor volume were also exhibited. (B) Tumor sections were stained with PCNA, MMP-2, MMP-9, E-cadherin and N-cadherin. Representive images of the immunohistochemistry assay were shown ( $\times 200)$.

insufficient RFA may also induce the genomic instability of HCC cells. However, the mechanisms involved in the process have not been elucidated and need to be studied in the further.

Metastasis is a multistage process that requires cancer cells to escape from the primary tumor, survive in the circulation, seed at distant sites and grow [17]. Metastasis has also always been a bottleneck in tumor prognosis and therapy [18]. Metastasis, both intrahepatic and extrahepatic, is of particular concern and occurs in more than half of HCC cases [19]. Our previous study suggested that tumor-associated endothelial cells after insufficient RFA could promote invasiveness of residual HCC cells in vitro [7]. Whether insufficient RFA could enhance invasive potential of HCC cells has not been determined. In this study, we found that SMMC7721 and Huh7 cells after insufficient RFA also exhibited enhanced migration and invasive potential. The EMT appears to be essential for cancerous cells to acquire the capability of migration and invasion and is a key driver to tumor cell translocation [20]. EMT is also a process whereby cells change from cobble-stone shapes that exhibit tight cell-cell contact into spindle-shape fibroblastlike shapes that lose cell-cell contact and cell polarity
[21-23]. The morphological changes of SMMC7721-H and Huh7-H cells were consistent with the characteristics of EMT. Down-regulation of E-cadherin and up-regulation of $\mathrm{N}$-cadherin, vimentin, $\alpha$-SMA, and fibronectin further confirmed that EMT occurred in HCC cells after insufficient RFA. Recently, Yoshida $\mathrm{S}$ et al. also demonstrated that sub-lethal heat treatment promoted EMT and enhanced the malignant potential of $\mathrm{HCC}$, which was partly consistent with our results [24]. The tail vein metastasis assay also showed that HCC cells after insufficient RFA exhibited enhanced pulmonary metastasis ability, which may further support our results in vivo. The results also showed that HCC cells after insufficient RFA had enhanced abilities of surviving in the circulation, colonization and outgrowth within a secondary organ, in which mesenchymal to epithelial transition (MET) plays a key role [25]. The complex mechanisms involved in the metastasis of HCC cells after insufficient RFA still need to be determined. Furthermore, we examined the growth of HCC cells after insufficient RFA in vivo. The expression of PCNA and N-cadherin was higher and the expression of E-cadherin was lower in SMMC7721-H cells than SMMC7721 cells, which was consistent with the results in vitro. 


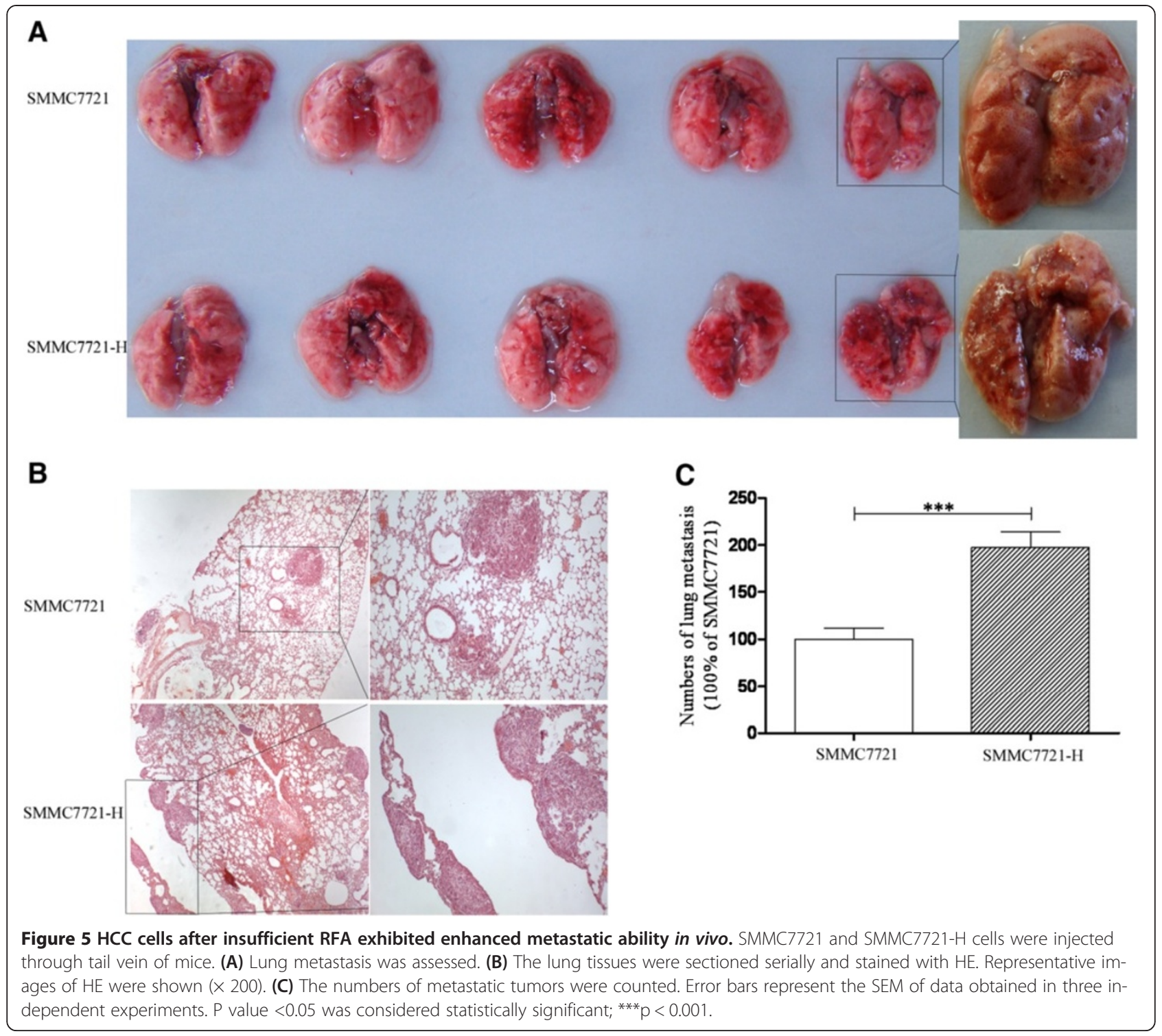

Lang BJ et al. reported that heat stress enhanced cell migration in both the lung A549, and breast MDA-MB468 human adenocarcinoma cell lines, with A549 cells also undergoing a partial EMT [26]. The heat stress used in their study was $42^{\circ} \mathrm{C} 30 \mathrm{~min}$, and the temperature was $47^{\circ} \mathrm{C} 5 \mathrm{~min}, 10 \mathrm{~min}, 15 \mathrm{~min}, 20 \mathrm{~min}$ and $25 \mathrm{~min}$ in our study, however, the results was partly consistent. Although Lang BJ et al. demonstrated that heat stress promoted cell migration independent of heat shock factor 1, the mechanisms involved in the process had not been further determined. Recently, Akt and ERK signaling pathways have been reported to play a key role in the EMT of cancers. Hepatitis B virus X protein repressed miRNA-148a to enhance tumorigenesis through Akt and ERK mediating EMT of HCC [27]. ERK/Akt also regulated EZH2 and E-cadherin to influence the
EMT of cancer [28]. TMPRSS4 and TAAC3 promoted EMT through the activation of PI3K/Akt and ERK signaling pathways $[29,30]$. Akt and ERK signaling pathways also mediated HGF $[31,32]$, TGF- $\beta$ [33,34], and EGFR $[35,36]$ inducing EMT. In our study, HCC cells after insufficient RFA exhibited higher expression of p-Akt and p-ERK1/2, and PI3K inhibitor, LY294002, and ERK inhibitor, PD98059, significantly inhibited the expression of p-Akt and p-ERK1/2 respectively. LY294002 and PD98059 suppressed the migratory and invasive abilities of SMMC7721-H and Huh7-H cells, and also inhibited the higher expression of $\mathrm{N}$-cadherin, fibronectin, vimentin, $\alpha$-SMA and snail in SMMC7721-H and Huh7$\mathrm{H}$ cells. Our results suggested that insufficient RFA may induce the EMT of HCC cells through Akt and ERK signaling pathways. 


\section{Conclusions}

Our results suggest that insufficient RFA could directly promote the invasiveness and metastasis of HCC cells. Insufficient RFA may promote the EMT of HCC cells through Akt and ERK signaling pathways.

\section{Additional files}

Additional file 1: Insufficient RFA promoted EMT of Huh7 cells through Akt and ERK1/2 signaling pathways. (A) The expression of p-Akt, Akt, p-ERK1/2, ERK2 and snail in Huh7 and Huh7-H cells were assessed by western blot. (B) LY294002 or PD98059 was used to treat HCC cells, and western blot was used to determine the expression of p-Akt, Akt, p-ERK1/2, ERK2, E-cadherin, N-cadherin, and snail. (C-D) LY294002 or PD98059 was used to treat Huh7 and Huh7-H cells, and migration (C) and invasion (D) of Huh7 and Huh7-H were evaluated. Error bars represent the SEM of data obtained in three independent experiments. $P$ value $<0.05$ was considered statistically significant; ${ }^{* * *} p<0.001$, ${ }^{* *} \mathrm{p}<0.01$, ns, no significance.

Additional file 2: Curves of mice body weight in the xenograft assays and tail vein metastatic assays. Mice body weight in the xenograft assays (A) and tain vein metastatic assays (B) were shown.

\section{Competing interests}

The authors declare that they have no competing interests.

\section{Authors' contributions}

SYD, JK and FDK carried out the experiments and drafted the manuscript. JGK and SHW participated in the sequence alignment. LMZ and WBS conceived the study and coordination and helped to draft the manuscript. JG, SK, and XMD participated in the design of the study. All authors read and approved the final manuscript.

\section{Acknowledgments}

This project was supported by Grants 320675007131 and 32067501207 from the Dr. Jieping Wu Medical Foundation, Clinical-Basic Medicine Cooperation Fund of Capital Medical University (1300171711), the Program for Medical Academic backbone (Beijing, China, 2009-3-11), 2010CB912504 and 2011 CB503900 from "973" National S\&T Major Project, 81170101, 30821001, and 81370235 from the National Natural Science Foundation of China, and 7122106 from the Natural Science Foundation of Beijing, China.

\section{Author details}

${ }^{1}$ Department of Hepatobiliary Surgery, Beijing Chaoyang Hospital, Capital Medical University, Beijing 100043, China. ${ }^{2}$ The Institute of Cardiovascular Sciences and Institute of Systems Biomedicine, School of Basic Medical Sciences, Peking University Health Science Center, Key Laboratory of Molecular Cardiovascular Sciences of Education Ministry, and Key Laboratory of Cardiovascular Molecular Biology and Regulatory Peptides of Health Ministry, Beijing 100191, China. ${ }^{3}$ The Neuroscience Research Institute \& Department of Neurobiology, School of Basic Medical Sciences, Key Laboratory for Neuroscience, Ministry of Education/National Health and Family Planning Commission, Peking University, Beijing, 100191, China.

Received: 24 June 2013 Accepted: 24 October 2013

Published: 29 October 2013

\section{References}

1. El-Serag HB: Hepatocellular carcinoma. N Engl J Med 2011, 365:1118-1127.

2. Maluccio M, Covey A: Recent progress in understanding, diagnosing, and treating hepatocellular carcinoma. CA Cancer J Clin 2012, 62:394-399.

3. Kim KW, Lee JM, Klotz E, Kim SJ, Kim SH, Kim JY, Han JK, Choi BI: Safety margin assessment after radiofrequency ablation of the liver using registration of preprocedure and postprocedure CT images. AJR Am J Roentgenol 2011, 196:W565-W572.

4. Nijkamp MW, van der Bilt JD, de Bruijn MT, Molenaar IQ, Voest EE, van Diest PJ, Kranenburg O, Borel Rl: Accelerated perinecrotic outgrowth of colorectal liver metastases following radiofrequency ablation is a hypoxia-driven phenomenon. Ann Surg 2009, 249:814-823.

5. Nijkamp MW, Hoogwater FJ, Steller EJ, Westendorp BF, van der Meulen TA, Leenders MW, Borel Rl, Kranenburg O: CD95 is a key mediator of invasion and accelerated outgrowth of mouse colorectal liver metastases following radiofrequency ablation. $J$ Hepatol 2010, 53:1069-1077.

6. Nikfarjam M, Muralidharan V, Christophi C: Altered growth patterns of colorectal liver metastases after thermal ablation. Surgery 2006, 139:73-81.

7. Kong J, Kong L, Kong J, Ke S, Gao J, Ding X, Zheng L, Sun H, Sun W: After insufficient radiofrequency ablation, tumor-associated endothelial cells exhibit enhanced angiogenesis and promote invasiveness of residual hepatocellular carcinoma. J Transl Med 2012, 10:230.

8. Kong J, Kong J, Pan B, Ke S, Dong S, Li X, Zhou A, Zheng L, Sun WB: Insufficient radiofrequency ablation promotes angiogenesis of residual hepatocellular carcinoma via HIF-1alpha/VEGFA. PLOS One 2012, 7:e37266.

9. Ke S, Ding XM, Kong J, Gao J, Wang SH, Cheng Y, Sun WB: Low temperature of radiofrequency ablation at the target sites can facilitate rapid progression of residual hepatic VX2 carcinoma. J Trans/ Med 2010, 8:73.

10. Obara K, Matsumoto N, Okamoto M, Kobayashi M, Ikeda H, Takahashi H, Katakura Y, Matsunaga K, Ishii T, Okuse C, et al: Insufficient radiofrequency ablation therapy may induce further malignant transformation of hepatocellular carcinoma. Hepatol Int 2008, 2:116-123.

11. Valastyan S, Weinberg RA: Tumor metastasis: molecular insights and evolving paradigms. Cell 2011, 147:275-292

12. Gupta GP, Massague J: Cancer metastasis: building a framework. Cell 2006, 127:679-695.

13. De Craene B, Berx G: Regulatory networks defining EMT during cancer initiation and progression. Nat Rev Cancer 2013, 13:97-110.

14. Frisch SM, Schaller M, Cieply B: Mechanisms that link the oncogenic epithelial-mesenchymal transition to suppression of anoikis. J Cell Sci 2013, 126:21-29.

15. Tao YM, Huang JL, Zeng S, Zhang S, Fan XG, Wang ZM, Yang HX, Yuan XH Wang P, Wu F, et al: BTB/POZ domain-containing protein 7: epithelialmesenchymal transition promoter and prognostic biomarker of hepatocellular carcinoma. Hepatology 2013, 57:2326-2337.

16. Cucchetti A, Piscaglia F, Cescon M, Colecchia A, Ercolani G, Bolondi L, Pinna AD: Cost-effectiveness of hepatic resection versus percutaneous radiofrequency ablation for early hepatocellular carcinoma. $J$ Hepatol 2013, 59:3000-3007.

17. Joyce JA, Pollard JW: Microenvironmental regulation of metastasis. Nat Rev Cancer 2009, 9:239-252.

18. Tao ZH, Wan JL, Zeng LY, Xie L, Sun HC, Qin LX, Wang L, Zhou J, Ren ZG, $L i Y X$, et al: miR-612 suppresses the invasive-metastatic cascade in hepatocellular carcinoma. J Exp Med 2013, 210:789-803.

19. Wang $X Q$, Zhang W, Lui EL, Zhu Y, Lu P, Yu X, Sun J, Yang S, Poon RT, Fan ST: Notch1-Snail1-E-cadherin pathway in metastatic hepatocellular carcinoma. Int J Cancer 2012, 131:E163-E172.

20. Polyak K, Weinberg RA: Transitions between epithelial and mesenchymal states: acquisition of malignant and stem cell traits. Nat Rev Cancer 2009, 9:265-273.

21. Yang AD, Fan F, Camp ER, van Buren G, Liu W, Somcio R, Gray MJ, Cheng H, Hoff PM, Ellis LM: Chronic oxaliplatin resistance induces epithelial-tomesenchymal transition in colorectal cancer cell lines. Clin Cancer Res 2006, 12:4147-4153.

22. Tsukamoto H, Shibata K, Kajiyama H, Terauchi M, Nawa A, Kikkawa F: Irradiation-induced epithelial-mesenchymal transition (EMT) related to invasive potential in endometrial carcinoma cells. Gynecol Oncol 2007, 107:500-504.

23. Xiong W, Ren ZG, Qiu SJ, Sun HC, Wang L, Liu BB, Li QS, Zhang W, Zhu XD, Liu $L$, et al: Residual hepatocellular carcinoma after oxaliplatin treatment has increased metastatic potential in a nude mouse model and is attenuated by Songyou Yin. BMC Cancer 2010, 10:219.

24. Yoshida S, Kornek M, Ikenaga N, Schmelzle M, Masuzaki R, Csizmadia E, Wu Y, Robson SC, Schuppan D: Sub-lethal heat treatment promotes epithelial-mesenchymal transition and enhances the malignant potential of hepatocellular carcinoma. Hepatology 2013. in press.

25. Brabletz T: EMT and MET in metastasis: where are the cancer stem cells? Cancer Cell 2012, 22:699-701. 
26. Lang BJ, Nguyen L, Nguyen HC, Vieusseux UL, Chai RC, Christophi C, Fifis T, Kouspou MM, Price JT: Heat stress induces epithelial plasticity and cell migration independent of heat shock factor 1. Cell Stress Chaperones 2012, 17:765-778.

27. Xu X, Fan Z, Kang L, Han J, Jiang C, Zheng X, Zhu Z, Jiao H, Lin J, Jiang K, et al: Hepatitis $B$ virus $X$ protein represses miRNA-148a to enhance tumorigenesis. J Clin Invest 2013, 123:630-645.

28. Ferraro A, Mourtzoukou D, Kosmidou V, Avlonitis S, Kontogeorgos G, Zografos G, Pintzas A: EZH2 is regulated by ERK/AKT and targets integrin alpha2 gene to control Epithelial-Mesenchymal Transition and anoikis in colon cancer cells. Int I Biochem Cell Biol 2013, 45:243-254.

29. Kim S, Kang HY, Nam EH, Choi MS, Zhao XF, Hong CS, Lee JW, Lee JH, Park YK: TMPRSS4 induces invasion and epithelial-mesenchymal transition through upregulation of integrin alpha5 and its signaling pathways. Carcinogenesis 2010, 31:597-606.

30. Ha GH, Park JS, Breuer EK: TACC3 promotes epithelial-mesenchymal transition (EMT) through the activation of PI3K/Akt and ERK signaling pathways. Cancer Lett 2013, 332:63-73.

31. Tanahashi T, Osada S, Yamada A, Kato J, Yawata K, Mori R, Imai H, Sasaki Y, Saito S, Tanaka Y, et al: Extracellular signal-regulated kinase and Akt activation play a critical role in the process of hepatocyte growth factor-induced epithelial-mesenchymal transition. Int J Oncol 2013 42:556-564.

32. Ogunwobi OO, Liu C: Hepatocyte growth factor upregulation promotes carcinogenesis and epithelial-mesenchymal transition in hepatocellular carcinoma via Akt and COX-2 pathways. Clin Exp Metastasis 2011, 28:721-731.

33. Godoy P, Hengstler JG, Ilkavets I, Meyer C, Bachmann A, Muller A, Tuschl G, Mueller SO, Dooley S: Extracellular matrix modulates sensitivity of hepatocytes to fibroblastoid dedifferentiation and transforming growth factor beta-induced apoptosis. Hepatology 2009, 49:2031-2043.

34. Katsuno Y, Lamouille S, Derynck R: TGF-beta signaling and epithelialmesenchymal transition in cancer progression. Curr Opin Oncol 2013, 25:76-84.

35. Zuo JH, Zhu W, Li MY, Li XH, Yi H, Zeng GQ, Wan XX, He QY, Li JH, Qu JQ, et al: Activation of EGFR promotes squamous carcinoma SCC10A cell migration and invasion via inducing EMT-like phenotype change and MMP-9-mediated degradation of E-cadherin. J Cell Biochem 2011, 112:2508-2517.

36. Gan Y, Shi C, Inge L, Hibner M, Balducci J, Huang Y: Differential roles of ERK and Akt pathways in regulation of EGFR-mediated signaling and motility in prostate cancer cells. Oncogene 2010, 29:4947-4958.

doi:10.1186/1479-5876-11-273

Cite this article as: Dong et al: Insufficient radiofrequency ablation promotes epithelial-mesenchymal transition of hepatocellular carcinoma cells through Akt and ERK signaling pathways. Journal of Translational Medicine 2013 11:273.

\section{Submit your next manuscript to BioMed Central and take full advantage of:}

- Convenient online submission

- Thorough peer review

- No space constraints or color figure charges

- Immediate publication on acceptance

- Inclusion in PubMed, CAS, Scopus and Google Scholar

- Research which is freely available for redistribution 